\title{
RESEARCH OF THE EFFECT OF INTENSIVE COOLING ON THE CHARACTERISTICS OF THE HOT-ROLLED STRIP
}

\author{
${ }^{1}$ Evgeny SOLDATOV, ${ }^{2}$ Alexander MUNTIN \\ 1VSW - Vyksa Steel Works, Vyksa, Russian Federation, soldatovea@vsw.ru \\ ${ }^{2}$ Bauman Moscow State Technical University, Faculty of Engineering Technology, Moscow, \\ Russian Federation, muntin av@vsw.ru
}

https://doi.org/10.37904/metal.2019.836

\begin{abstract}
The main methods of cooling of hot-rolled strip at continuous mills and casting and rolling complexes are considered. Based on the data of the influence of the cooling conditions on mechanical properties of strip, the actuality of the existing equipment and automation modernization is shown (within the boundaries of the runout-table layout). An assessment of the effect of the cooling rate and the placement of water cooling equipment on the microstructure and mechanical characteristics is made. The paper summarizes the research and practical experience of accelerated and intensified water cooling at laboratory equipment and industrial rolling mill. During the production at industrial rolling mill, it has been established that for different thicknesses and initial chemical compositions, it's possible to increase strength properties and cold-resistance of final strip. The transformation of the microstructure of steel by varying the conditions of post-deformation cooling contributes to obtaining rolled products of various strength classes from steel of the same chemical composition.
\end{abstract}

Keywords: Continuous hot strip mill, hot-rolled steel, intensive cooling, water alloying, mechanical properties

\section{INTRODUCTION}

The effect of the accelerated water cooling of hot rolled strips after rolling on hot strip mill is well known and studied by many researchers in recent decades. Accelerated cooling allows control the temperature of the strip before coiling, which directly affects the microstructure and mechanical properties of final product. Nowadays the increasing of efficiency of rolling process is one of the strongest trends in industry. For example, new types of casting and rolling complexes are making a huge step forward in strip production $[1,2]$ and they require modern developments in different equipment, including strip cooling systems. Especially it takes into account in case of production difficult value-added products or in case of optimization technology of conventional grades $[3,4]$. The aim of the paper to show modern solutions in strip cooling from the points of view of laboratory study and real industrial experience at hot strip mill of casting and rolling complex.

\subsection{Overview of Colling Systems}

Among the strip cooling installations, the use of collectors with a laminar flow of water is most common. These include the design of U-tube and Water Wall (Figure 1), but they have natural limitations to increase the cooling rate.

Modern systems of intensive cooling of the strip or Ultra-Fast Cooling (UFC allow to increase the cooling rate several times, without installing them along the entire length of the runout-table $[5,6]$.

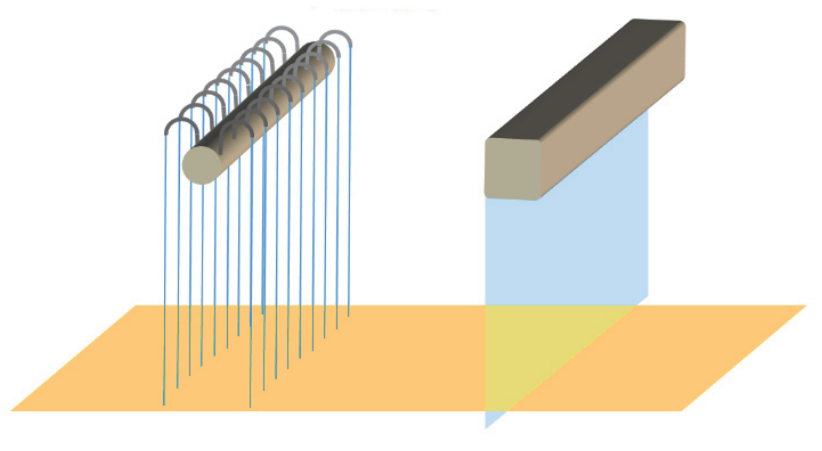

Figure 1 Laminar cooling strips 
The vast majority of intensive strip cooling systems is installed in China and Germany. These are mainly intensive cooling plants of the SMS Group (Compact Cooling brand) and Primetals (Power Cooling brand) companies. On some mills in the world, Japanese equipment Super-OLAC and equipment of the Chinese company Sinosteel are installed. Usually UFCsystems includes large number of nozzles or holes and water is supplied under high pressure (Figure 2).

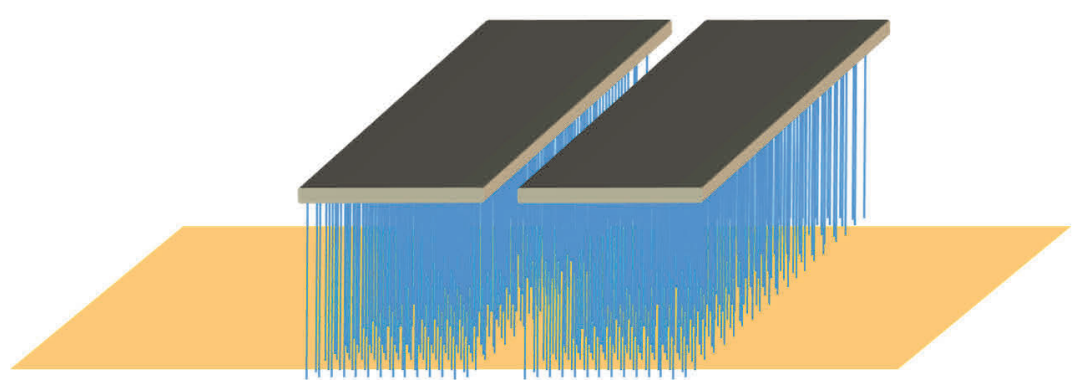

Figure 2 Principal scheme of collectors of intensive cooling

Analysis of the data showed that the cooling rate for such plants varies in the range of $70-90{ }^{\circ} \mathrm{C} / \mathrm{sec}$ for strip with a thickness of $10 \mathrm{~mm}$ and $20-40{ }^{\circ} \mathrm{C} / \mathrm{sec}$ for strip with a thickness of more than $20 \mathrm{~mm}$ (Figure 3).

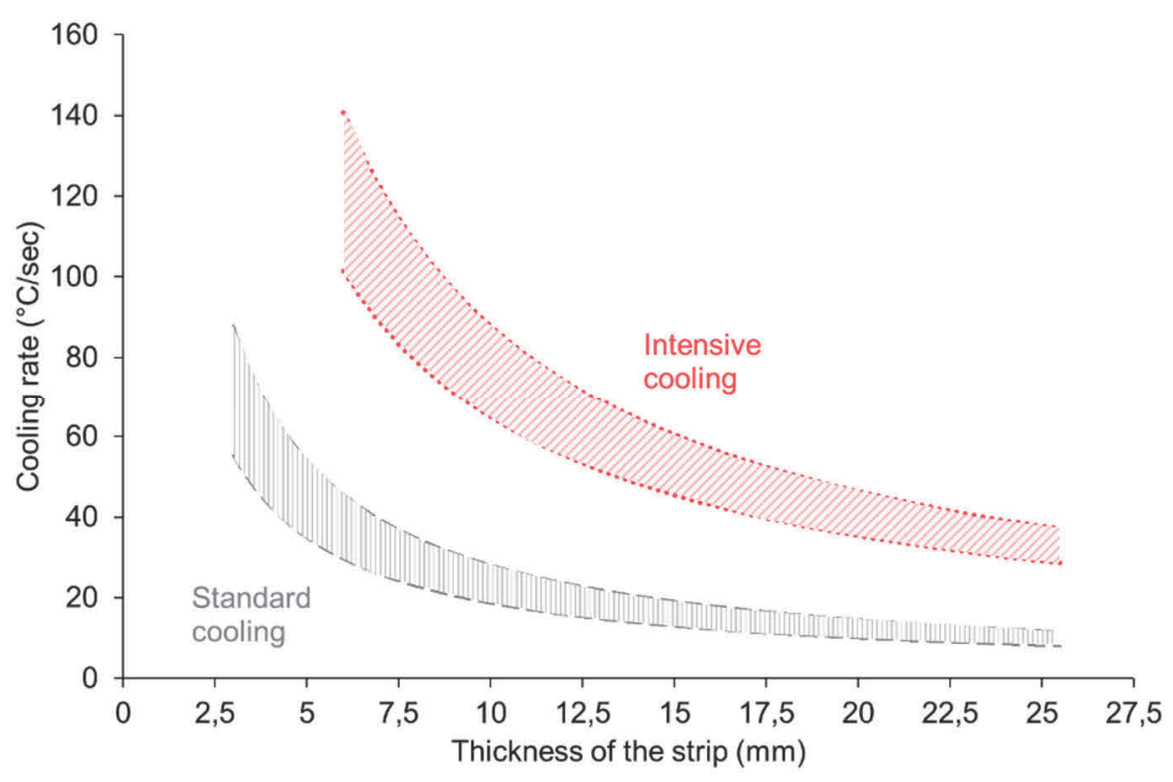

Figure 3 Maximum cooling rates of the strip in the runout-table

Several published foreign papers present the results of a study of the influence of intensive cooling strategies on the mechanical properties of finished rolled products $[7,8]$. The general increase in strength characteristics in the range from 20 to $80 \mathrm{MPa}$ for steel grades with low values of yield strength and tensile strength, for example, C-Mn steel Q235B, is shown.

There are several concepts for the use of intensive cooling in CHSM, the differences of which lie in the location of the installation in the interval between the finishing mills and the coil. Option at the beginning is used to harden the metal. The effect is achieved by rapid cooling of the metal immediately after the finish rolling. The option at the end is used to obtain unique properties by achieving low temperatures in front of the coiler. The option of placement of installations at the beginning and at the end combines in itself the achievements of both options, plus due to this, the length of the runout-table is reduced. 


\section{DEVELOPMENT OF COOLING STRATEGIES}

Analysis of equipment layout on the runout-table of CHSM 1950 (Vyksa, Russia) revealed 4 cooling strategies ( 2 conventional laminar and 2 new intensive): continuous laminar cooling over the entire length of the discharge runout-table (CONT); laminar cooling with maximum water consumption at the beginning of the discharge runout-table (FAST); intensified cooling with a site of accelerated cooling at the exit from the finishing stands (INT); intensified cooling with maximum use of the accelerated cooling section (INT MAX). First three strategies have the same coiling temperature. The fourth strategy "INT MAX" implies a more efficient use of intensive cooling sections, while the coiling temperature is lower than in other strategies. An example of cooling curves for a $6 \mathrm{~mm}$ thick strip is shown in the Figure 4 .

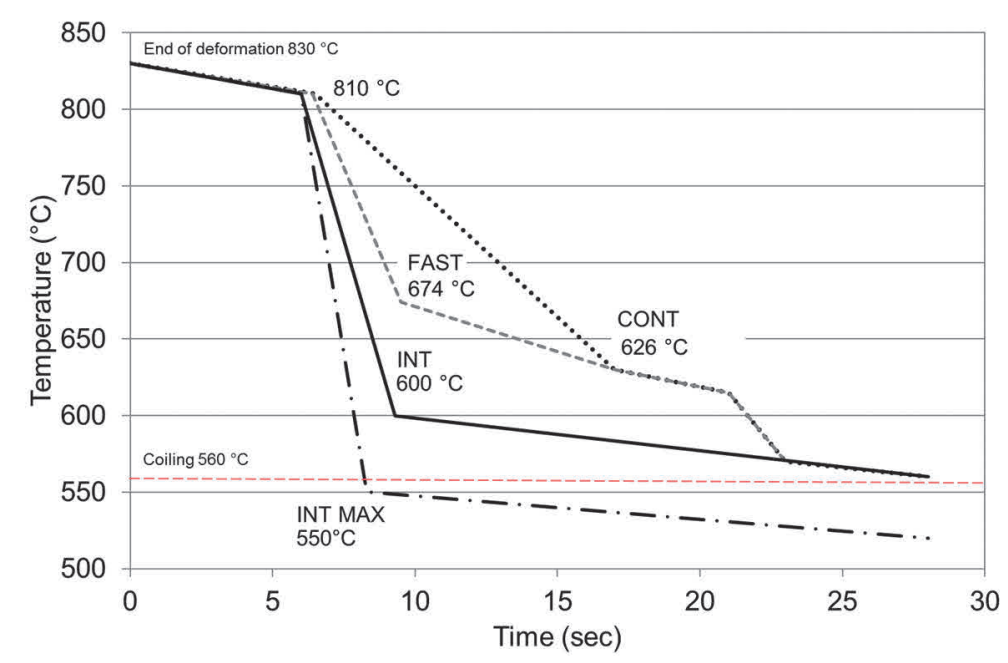

Figure 4 Cooling curves for a $6 \mathrm{~mm}$ thick strip

The graph of cooling rate of hot-rolled strip from 2 to $14 \mathrm{~mm}$ is shown in the Figure 5 .

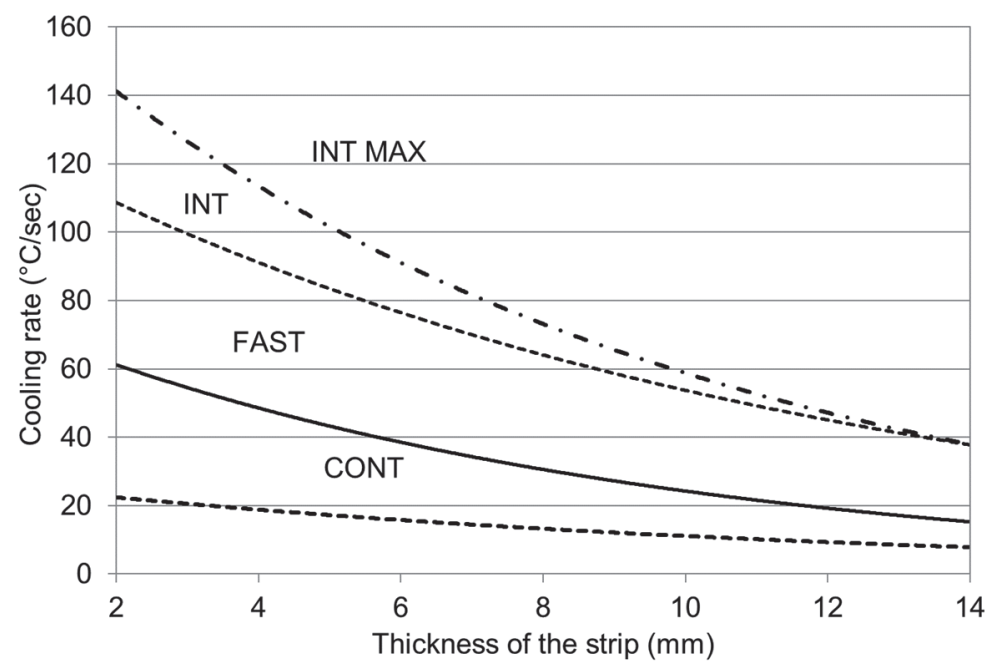

Figure 5 Cooling rates on the main water cooling section

Studies conducted on samples of steel X52-X65 showed that the currently implemented FAST strategy allows to increase the tensile strength by an amount from $3 \mathrm{MPa}$ (for X52) to $13 \mathrm{MPa}$ (for X65) compared to the CONT strategy. The use of strategies INTENSIVE and INTENSIVE MAX can increase the tensile strength relative to FAST by 26-41 MPa and 31-52 MPa, respectively. The Figures 6 show a characteristic change in the microstructure of the car during the transition from the "FAST" mode to the "INT MAX" mode. 

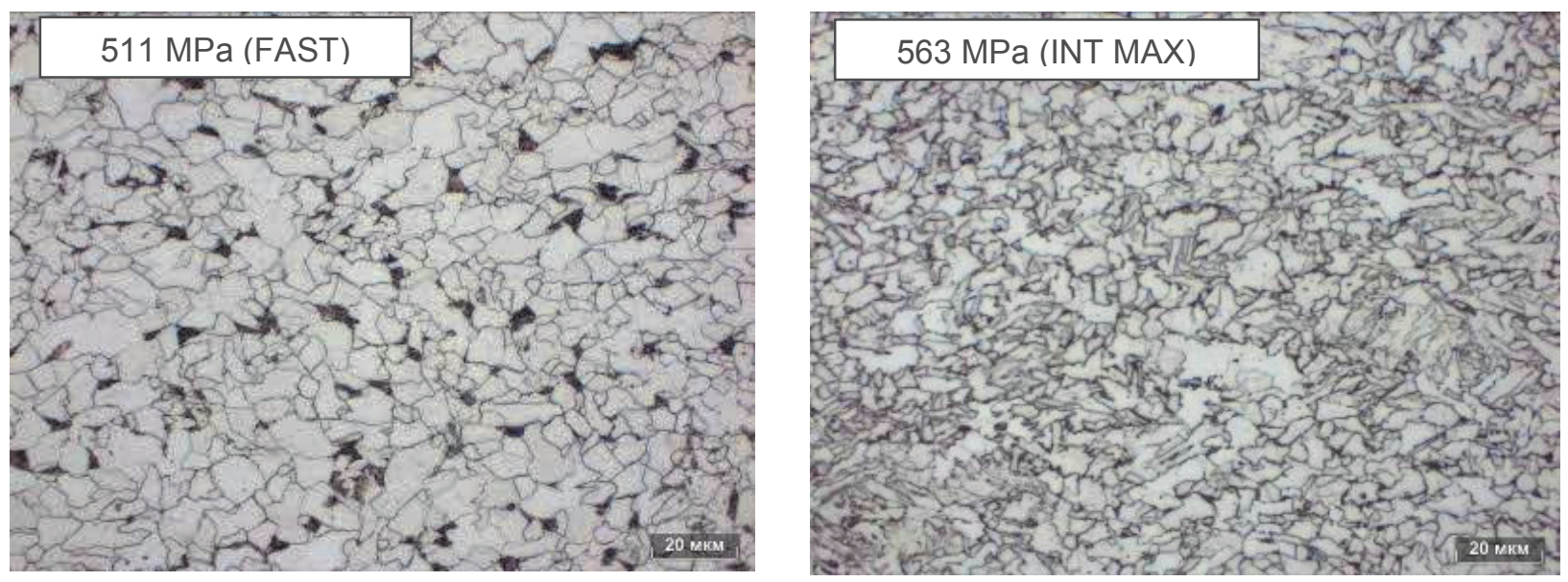

Figure 6 Microstructure of samples after different cooling strategies

During the metallographic study, it was shown that for X52 steel, the structure with a significant proportion of perlite transforms into a fine-grained ferrite-bainite structure with virtually no perlite. In steel X65 with an already rather small initial structure at FAST, an even greater content of the bainitic component can be obtained.

\section{SELECTION OF PLACES OF INTENSIVE COOLING INSTALLATION}

The length of the CHSM 1950 is about 100 meters. At such length the variant of placing of an installation of intensive cooling is actual, both at an exit from a finishing mill (beginning of the runout table) and before a coiling of a strip (end of runout table).

In order to study the effect of the location of intensive cooling sections on cooling parameters, several options for installing sections along the length of the runout-table were considered. For the calculations, a specially developed statistical model was used. Thanks to it, the conditions of cooling in the case of using sections at the beginning and at the end of the runout-table, as well as two-stage cooling, are simulated. According to the calculations, the installation of intensive sections at first allows increasing the cooling rate to $\approx 70{ }^{\circ} \mathrm{C} / \mathrm{s}$ for a thickness of $8 \mathrm{~mm}$. At the same time, with the same set temperature in front of the coiler, the temperature of the cooling end when using intensive strategies is lower by 20 and $45 \mathrm{C}$ relative to the standard modes, which will further increase the strength properties of the rolled strip. Due to the use of intensive sections at the end of the runout-table, the air cooling time after rolling increases by approximately 5 seconds for a thickness of 8 $\mathrm{mm}$ and the cooling rate increases in comparison with the LATE mode. However, it should be noted that the calculated number of sections will not be enough to obtain unique properties of dual-phase steel (for example with MA). The installation option may be considered partly at the beginning and partly at the end of the runouttable. In this case, a more efficient two-stage cooling mode will be implemented. So with the proposed modes, the pause between cooling can be increased by more than 1.5 times compared with the standard mode.

In order to confirm this data under laboratory conditions, an experiment was conducted, the purpose of which was to determine the effect of temperature-time parameters on the final mechanical properties. The results showed that the temperature of the end of the first cooling affects the grain size (lower temperature, finer grain). The presence of early cooling contributes to the formation of irregular grain boundaries. The longer is the pause length, the greater the size of the ferrite and the volume fraction of the second phase. Lowering the temperature at the end of late cooling allows for a larger volume of the MA-component. To ensure high strength, a large proportion of solid constituents is required, their dispersity affects viscosity properties, and plasticity requires a large volume of ferrite together with its size. A structure close to these parameters can be formed in case of bigger length of the runout-table with a number of intensive cooling section at the beginning and before coiling. 


\section{RESEARCH OF THE EFFECT OF COOLING RATE}

From the analysis performed, it was concluded that primary attention should be paid to the option of installing intensive sections at the beginning of the runout-table. This option is most effective in the framework of the runout-tables of a small length (up to $100 \mathrm{~m}$ ). The industrial intensive cooling installation designed and implemented in a joint project of OMK JSC and Danieli Company is being tested at CHSM 1950 (Vyksa, Russia). It consists of 4 sections of intensive cooling with a maximum total water flow rate (top and bottom) $3200 \mathrm{~m}^{3} /$ hour. The cooling efficiency of the strip after a partial upgrade of the cooling modules of the Water Wall system to the new Cooling Box modules has been doubled. The actual results on the cooling rate of rolled products with a thickness of $10 \mathrm{~mm}$ were $65-70^{\circ} \mathrm{C} / \mathrm{s}$. With the transition to new cooling strategies using all the possibilities of new installations, the increase in tensile strength and yield strength of rolled products, ceteris paribus, averaged $\approx 30 \mathrm{MPa}$, maximum $\approx 60 \mathrm{MPa}$. In addition, a comparative experiment conducted to assess the effect of the cooling rate and micro-alloying of steel on grain grinding processes in rolled products showed that due to high-speed post-deformation cooling, it is possible to achieve the identity of rolled microstructures with and without micro-alloying. The average conditional grain size of micro-alloyed steel was 7.24 microns, without micro-alloying - 7.98 microns. During industrial experiments, it was also shown that the use of higher cooling rate makes it possible to obtain a strength group up to X60 with improved cold-resistance characteristics from the typical chemical composition of X52 strength class.

\section{CONCLUSION}

Installation of modern intensive cooling sections for hot strip mills and casting and rolling complexes is one of the effective ways, how to improve flexibility of cooling at runout table. Early position at the beginning of runout table allows increasing the strength and toughness of final product. The position at the end of runout table (also together with early position) is a good basis for archiving dual-phase microstructure including MAcomponents under certain conditions.

\section{REFERENCES}

[1] MUNTIN, A. V. Advanced Technology of Combined Thin Slab Continuous Casting and Steel Strip Hot Rolling. Metallurgist. 2019. vol. 62, no. 9-10, pp 900-910.

[2] STULOV, V.V. and ALDUNIN, A.V. Production of hot-rolled sheet of specified quality by a new slab-casting technology. Steel in Translation. 2017. vol. 47, no. 10. pp. 645 - 649.

[3] ChERVONNYI, A. V., RINGINEN, D. A., CHASTUKHIN, A. V., EFRON, L. I., MUNTIN, A. V., NAUMENKO, V. V. and BAGMET, O. A. Structure and Property Formation for Pipe Coiled Rolled Product During Manufacture Under Casting And Rolling Complex Conditions. Metallurgist. 2019. vol. 62, no. 9-10, pp 1012-1021.

[4] ALDUNIN, A. Development of method for calculation of structure parameters of hot-rolled steel strip for sheet stamping. Journal of Chemical Technology and Metallurgy. 2017. vol. 52, no. 4, pp. 737 - 740.

[5] HERMAN, J.C., LACROIX, J. and RICHE, P. Ultra-fast cooling in the hot-strip mill (Phase I). European Commission. Technical steel research. 2002, p 69.

[6] RICHE, P., HERMAN, J.C., Op de Beeck, M. and Rackel, H. Ultra-fast cooling in the hot-strip mill (Phase II). European Commission. Technical steel research. 2002. p. 58.

[7] PENG, L., LIU, X., ZHAO, X. and WU, D. Mathematic modeling on flexible cooling system in hot strip mill. J. Cent. South Univ. 2014. vol. 21, pp. 43-49.

[8] LIU, E., PENG, L., YUAN, G., WANG, Z., ZHANG, D. and WANG, G. Advanced run-out table cooling technology based on ultra-fast cooling and laminar cooling in hot strip mill. J. Cent. South Univ. 2012. vol. 19: pp. 1341-1345. 